\title{
The movement of potato virus Y (PVY) in the vascular system of potato plants
}

\author{
Brice Dupuis
}

Accepted: 20 July 2016 / Published online: 10 August 2016

(C) The Author(s) 2016. This article is published with open access at Springerlink.com

\begin{abstract}
Potato virus Y (PVY) is responsible for major viral diseases in most potato seed areas. It is transmitted by aphids in a non-persistent manner, and it is spread in potato fields by the winged aphids flying from an infected source plant to a healthy one. Six different PVY strains groups affect potato crops: $\mathrm{PVY}^{\mathrm{C}}, \mathrm{PVY}^{\mathrm{N}}, \mathrm{PVY}^{\mathrm{O}}$, $\mathrm{PVY}^{\mathrm{N}: \mathrm{O}}, \mathrm{PVY}^{\mathrm{NTN}}$, and $\mathrm{PVY}{ }^{\mathrm{N}-\mathrm{Wi}}$. Nowadays, $\mathrm{PVY} \mathrm{NTN}^{\mathrm{NTN}}$ and $P V Y^{\mathrm{N}-\mathrm{Wi}}$ are the predominant strains in Europe and the USA. After the infection of the leaf and accumulation of the virus, the virus is translocated to the progeny tubers. It is known that $\mathrm{PVY}^{\mathrm{N}}$ is better translocated than $\mathrm{PVY}^{\mathrm{O}}$, but little is known about the translocation of the other PVY strains. The translocation of PVY occurs faster in young plants than in old plants; this mature plant resistance is generally explained by a restriction of the cell-to-cell movement of the virus in the leaves. The mother tuber may play an important role in explaining mature plant resistance. PVY is able to pass from one stem to the other stems of the same plant through the vascular system of the mother tuber, but it is unknown whether this vascular link between stems is permanent during the whole life of the plant. Two greenhouse trials were set up to study the spread of PVY in the vascular
\end{abstract}

B. Dupuis

Agroscope, Institute for Plant Production Sciences IPS,

1260 Nyon 1, Switzerland

B. Dupuis $(\bowtie)$

Earth and Life Institute, Applied Microbiology, Phytopathology, Université catholique de Louvain UCL, Croix du Sud 2

*L7.05.03*, B-1348 Louvain-la-Neuve, Belgium

e-mail: brice.dupuis@agroscope.admin.ch system of the potato plant. The PVY-susceptible cultivar Charlotte was used for both trials. It was demonstrated that all stems growing from a PVY-infected tuber will become infected sooner or later, and that $\mathrm{PVY}^{\mathrm{N}-\mathrm{Wi}}$ translocates more efficiently to progeny tubers than $\mathrm{PVY}^{\mathrm{NTN}}$. It was also demonstrated that the progressive decay of the mother tuber in the soil reduces the possibility for virus particles to infect healthy stems through the vascular system of the mother tuber. This new element contributes to a better understanding of the mechanism of mature plant resistance.

Keywords Potato PVY - Mature plant resistance . Translocation $\cdot$ Primary infection $\cdot$ Secondary infection

\section{Introduction}

Potato virus Y (PVY, family Potyviridae, genus Potyvirus) is considered the most economically damaging potato virus in most countries that produce seed potatoes (Rolot 2005; Nolte et al. 2004). The virus is responsible for decreased yield and quality around the world. Most importantly, it is the main reason for rejection of seed lots for certification (Gray et al. 2010; Nolte et al. 2004). Six different PVY strains affect these potato crops. $\mathrm{PVY}^{\mathrm{O}}, \mathrm{PVY}^{\mathrm{C}}$, and $\mathrm{PVY}^{\mathrm{N}}$ are the historical strains. They were gradually replaced in Europe and North America by the strains $\mathrm{PVY}^{\mathrm{NTN}}, \mathrm{PVY}^{\mathrm{N}: \mathrm{O}}$, and $\mathrm{PVY}^{\mathrm{N}-\mathrm{Wi}}$, which are new recombinants of the historical strains (Karasev and Gray 2013b; Glais et al. 2002). PVY is transmitted by aphids in a non-persistent manner 
from an infected source plant to a healthy plant, giving rise to a so-called primary infected plant (Fereres and Moreno 2009). Later on, the virus particles migrate down to the progeny tubers; this migration is called the translocation of the virus (Debokx 1964). The following year, seed potatoes harvested from the primary infected plant will give rise to infected plants, usually called secondary infected plants (Malnoe et al. 1994).

The breaking of the tuber's dormancy activates transport mechanisms through the phloem of the young tissues of the growing sprouts, which are actively draining sap out of the mother tuber. In PVY-infected tubers, this sap is loaded with virus particles that will concentrate at the rose end of the tuber where most of the sprouts are located (Basky and Almasi 2005; Gugerli and Gehriger 1980). Roots will grow horizontally from the base of the sprout while its apex will grow vertically, emerge from the soil, and give rise to a stem with branches and leaves. It is unknown whether all the stems growing from the same tuber will be infected through an upward systemic movement of PVY particles from the mother tuber.

The descending flow of sap from the stems to the progeny tubers, which allows the translocation of the virus, is better documented. Debokx (1964) was the first to study PVY translocation in potato plants, and to identify differences between varieties with respect to the rate of tuber infection in primary infected plants. Beemster (1976) confirmed those results and demonstrated that the efficacy of the translocation varied according to the PVY strain. He observed that $\mathrm{PVY}^{\mathrm{N}}$ primary infected plants presented a higher rate of infected progeny tubers compared to $\mathrm{PVY}^{\mathrm{O}}$ strains. Debokx (1964) described for the first time the mature plant resistance of potatoes to PVY. Mature plant resistance is a phenomenon in which the translocation of the virus from the leaves to the progeny tubers occurs faster in young plants than in old plants. In Debokx's experiment, mature plant resistance was more pronounced against the $\mathrm{PVY}^{\mathrm{O}}$ strain than against $\mathrm{PVY}^{\mathrm{N}}$ strains.

Resistance of mature plants to PVY appears about four weeks after emergence. The protection increases with plant age, reaching complete protection of the progeny tubers against infections at about 8-10 weeks after emergence (Sigvald 1985; Gibson 1991). Basky and Almasi (2005) investigated within-plant translocation further and observed that $\mathrm{PVY}^{\mathrm{N}}$ migrates faster than $\mathrm{PVY}^{\mathrm{O}}$ from infected leaves to other plant organs. After a cell-to-cell movement from the infected leaf cells to the vascular system, the virus was detected either in the upper or the lower segments of the stem, meaning that it can be transported by the flow of sap up and down the stem. It was also demonstrated that when a sprout is inoculated, the virus can systemically migrate to the other sprouts and develop symptoms in the stems later on (Basky and Almasi 2005; Valkonen and Rokka 1998; Draper et al. 2002).

Taken together, these results show that the virus is able to migrate through the phloem of the infected stem, and after reaching the vascular ring of the mother tuber it is able to colonize the vascular system of the other growing stems. This physical continuity of the vascular ring of the mother tuber with the vascular systems of the growing sprouts is clearly visible in Fig. 1 . As each stem has its own set of progeny tubers, if PVY succeeds in colonizing all the stems of the plant, it may also be capable of infecting all the plant's progeny tubers as well.

The first objective of this research is to track the spread of two PVY strains (PVY ${ }^{\mathrm{NTN}}$ and $\mathrm{PVY}^{\mathrm{N}-\text { Wilga}}$ ) from an infected mother tuber to the above-ground parts of the plant, and then from the haulms to the progeny tubers. The second objective of this research is to establish whether the earliness/moment of primary infection in one stem may influence the infection of the other stems of the same plant. This result will contribute to a better understanding of the resistance mechanisms implemented in mature plants. To achieve these two objectives, two greenhouse trials were managed in Changins (Switzerland): a movement and translocation trial, and a mature plant resistance trial.

\section{Materials and methods}

\section{Plant material}

For both greenhouse trials, the PVY-susceptible cultivar Charlotte was used (Schwaerzel et al. 2014). For the spread and translocation trial, 30 tubers infected by the PVY $^{\text {NTN }} 1317$ strain (Agroscope collection) and 30 tubers infected by the PVYN-Wilga 1315 strain (Agroscope collection) were used. Those PVY infected tubers were produced the previous year in the field in separated plots of 100 plants grown from healthy tubers. In each plot $4 \%$ of plants were inoculated with aforementioned PVY strains. The virus was then naturally transmitted to the neighboring plants through aphids. 
Fig. 1 Longitudinal section of a potato tuber with two growing stems. Legend: (a) vascular system of the first stem; (b) junction of the stems and mother tuber vascular systems; (c) vascular ring of the mother tuber; (d) vascular system of the second stem

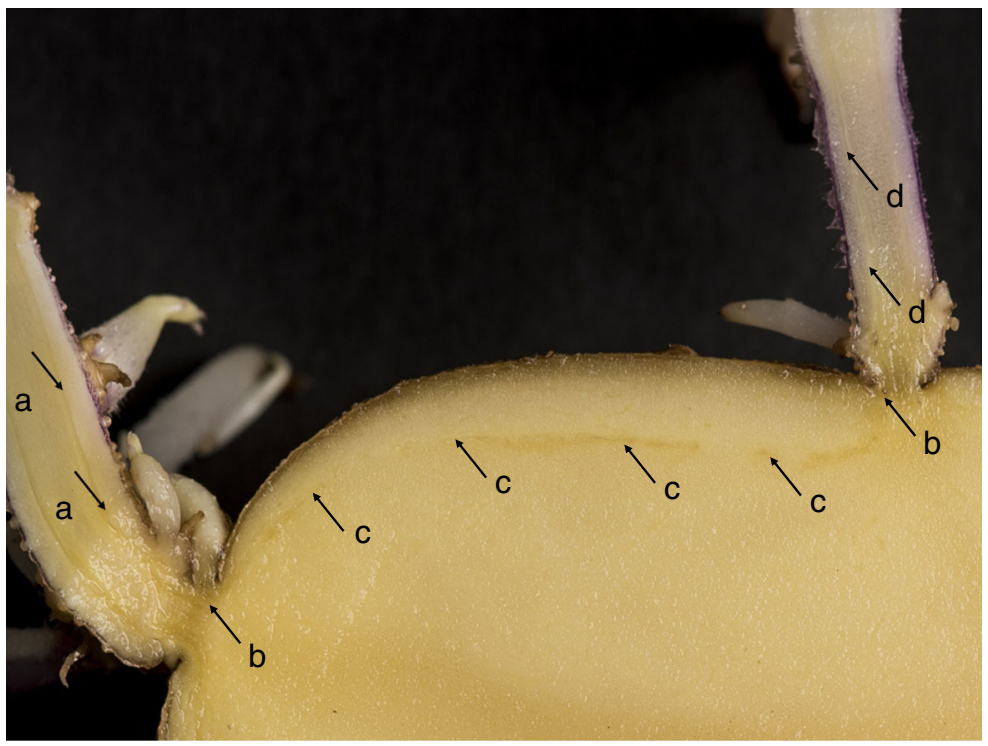

The identity of the inoculum was confirmed using a triplex RT-PCR as described by Rigotti and Gugerli (2007) and the identity of the strains in the 60 progeny tubers was confirmed using an enzyme-linked immunosorbent assay (ELISA). For the mature plant resistance trial, healthy tubers of cultivar Charlotte were used. They were analyzed using the same ELISA method to verify the presence/absence of the virus. Details of the ELISA method are presented below.

\section{PVY detection method}

PVY infections were tested in sprouting tubers using an ELISA method as described in Gugerli and Gehriger (1980). After harvest, a Rindite treatment was used to break dormancy and the treated tubers were then stored in the dark for 5 weeks at $22{ }^{\circ} \mathrm{C}$ and $80-90 \%$ of relative humidity to promote sprouting. After this storage period, sap is extracted from the vascular tissue underneath the sprouts with a drill (Bioreba AG, Reinach, Switzerland) and analyzed by ELISA. Two sets of monoclonal antibodies were used to verify the identity of the serotype, on the one hand an anti-PVY-N (191,073, Bioreba, specific for N strain) and on the other hand an anti-PVY-NOC (210,369, Bioreba). The samples reacting positively to the anti-PVY-NOC and negatively to the anti-PVY-N were declared infected by $\mathrm{PVY}^{\mathrm{N}-\text { Wilga }} 1315$ strain whereas the samples reacting positively to both antibodies were declared to be infected by $\mathrm{PVY}^{\mathrm{NTN}} 1317$ strain. For PVY detection in the stems, three leaflets were collected from the same stem: one in the upper, one in the medium, and one in the lower part of each stem. The three leaflets were ground together using Homex 6® (Bioreba AG, Reinach, Switzerland) and the sap was analyzed by ELISA. The same sets of antibodies as for tubers analysis were used to verify the identity of the PVY serotype in the leaflets (Bioreba AG, Reinach, Switzerland). A sample was considered positive when the optical density value was three times higher than the optical density of sap extracted from a healthy potato tuber.

\section{Management of trials}

For the movement and translocation trial, sprouts of the infected tubers were removed in order to maintain only three sprouts per tuber: one close to the rose end, one close to the heel end, and one in the middle. Following PVY detection underneath each sprout, the tubers were half-buried in a perlite bed in plastic pots $(19 \times 19 \times 18$ $\mathrm{cm})$. The pots were then dispatched in four distinct insect-proof greenhouses $\left(20{ }^{\circ} \mathrm{C}, 70 \%\right.$ relative humidity, and $12 \mathrm{~h}$ photoperiod) following a randomized block design. After development of the three stems (from the three sprouts), the stems were accordingly numbered and the pots were filled with compost. The plants were then grown until flowering and a leaf sample was taken for PVY detection. At the beginning of natural senescence, a sample of progeny tubers was analyzed by ELISA. 
For the mature plant resistance trial, the heathy tubers were planted in plastic pots $(19 \times 19 \times 18 \mathrm{~cm})$ filled with compost. The pots were randomized and maintained in an insect-proof greenhouse $\left(20{ }^{\circ} \mathrm{C}, 70 \%\right.$ relative humidity, and $12 \mathrm{~h}$ photoperiod). The plants were distributed into three groups. The first group was inoculated seven days after plant emergence (DAE). In order to do that, three leaves from one stem - one in the upper, one in the medium, and one in the lower part of each stemwere mechanically inoculated with the PVY ${ }^{\mathrm{NTN}} 1317$ strain (Agroscope collection) using carborundum (Perez 2011), and the inoculated stem was tagged. The other stems were numbered for traceability. The second group of plants was inoculated $21 \mathrm{DAE}$ and the last group 56 DAE. After inoculation, leaf samples were collected on each potato stem one, two, four, and six weeks after inoculation, in order to determine whether the stems were infected by PVY. The plants were grown until the beginning of natural senescence, around 90 days after emergence. This trial was repeated with an eightmonth interval between trials. For the first trial, 11 plants were allocated to each inoculation group, and for the second trial 15 plants were allocated to each group. For the replication of the trial, the tubers of each plant were counted and weighted. A sample of progeny tubers was analyzed by ELISA and it was establish whether the tubers were coming from the inoculated stem or from any other stems of the plant.

\section{Statistical analysis}

The data on infection percentages were transformed using the angular data transformation method (Dagnelie 1975) prior to running an analysis of variance (ANOVA). The software STATISTICA® (StatSoft, Tulsa, USA) was used for all analysis. For the movement and translocation trial, another two-factor ANOVA was run to compare the percentage of infected sprouts, stems, and tubers between the two PVY strains. The effects of the factors "PVY strain" and "sprout location" were tested as well as the interaction between those factors, and the "greenhouse" effect was used as a replication factor. For the mature plant resistance trial, a Cochran Q test (Cochran 1950) was used to test the effect of inoculation dates $(7,21$, or $56 \mathrm{DAE})$ on the probability of infection of stems after inoculation, and the probability of a new stem to be infected through the vascular system of the plant. A simple regression analysis was used to evaluate the effect of the infection date on the yield. Finally, a two-factor ANOVA was run to compare the percentage of infected stems. The effects of the factors "day of inoculation" and "replication of the trial" were tested, as well as the interaction between these factors.

\section{Results}

Movement and translocation trial

We did not observe any effect of the insertion site of the sprout on the probability of sprout becoming infected $(p>0.05)$. However, all the sprouts growing from infected tubers finally became stems in which the virus was detected (Table 1), proving that even if the infection was not present in the vascular system of the sprout itself, it may have arrived later from other parts of the mother tuber. Part of the sprouts never grew up (Table 1), meaning that the de-sprouting of the tuber before planting was not sufficient to break the apical dominance of the main sprout. As presented in Table 1, the rate of PVY-infected sprouts was significantly higher $(p<0.001)$ for $\mathrm{PVY}^{\mathrm{N} \text {-Wilga }}$ infected tubers $(84 \%)$ than for PVY ${ }^{\mathrm{NTN}}$ infected tubers $(69 \%)$. The $\mathrm{PVY}^{\mathrm{N}-W i l g a}$ stem infection was efficiently transmitted to the progeny tubers, as $99 \%$ of them were infected (Table 1). The transmission of PVY ${ }^{\mathrm{NTN}}$ was significantly lower than $\mathrm{PVY}^{\mathrm{N}-\text { Wilga }}$, with no more than $43 \%$ of the progeny tubers infected $(p<0.001)$.

\section{Mature plant resistance trial}

The results indicate that not all the inoculated stems developed infections: the later the inoculation was done, the fewer infected stems were observed $(p<0.01)$. At early plant senescence times, PVY was detected in $92 \%$ and $81 \%$ of the stems inoculated at 7 and at 21 days after emergence, respectively. In contrast, it was detected in only $50 \%$ of the stems inoculated at 56 days after emergence (Fig. 2). However, all the progeny tubers $(n=36)$ harvested from the inoculated stems were infected by PVY, whatever the date of inoculation.

The probability for a non-inoculated stem to get infected through the movement of the virus particle along the vascular system of the mother tuber also varied as a function of the inoculation date $(p<0.001)$. The results of the last ELISA analysis done before plant senescence show that $92 \%$ of the stems of 
Table 1 Evolution of the PVY infection percentage of potato plants during the different phases of their development from sprouts to stems and progeny tubers. Two groups are presented: the plants infected by $\mathrm{PVY} \mathrm{Y}^{\mathrm{N}-\mathrm{Wilga}}$ and by $\mathrm{PVY}^{\mathrm{NTN}}$ strains. For each group, the location of the sprout on the mother-tuber is specified

\begin{tabular}{|c|c|c|c|c|c|c|}
\hline \multirow{2}{*}{$\frac{\text { PVY strain }}{\mathrm{PVY}^{\mathrm{NTN}}}$} & \multicolumn{2}{|c|}{ Percentage of infeceted sprouts } & \multicolumn{2}{|c|}{ Percentage of infected stems } & \multicolumn{2}{|c|}{ Percentage of infected tubers } \\
\hline & $69 \%$ & $(n=90)$ & $100 \%$ & $(n=51)$ & $43 \%$ & $(n=202)$ \\
\hline Rose end sprout & $63 \%$ & $(n=30)$ & $100 \%$ & $(n=22)$ & $35 \%$ & $(n=106)$ \\
\hline Middle sprout & $73 \%$ & $(n=30)$ & $100 \%$ & $(n=15)$ & $42 \%$ & $(n=56)$ \\
\hline Heel end sprout & $70 \%$ & $(n=30)$ & $100 \%$ & $(n=14)$ & $59 \%$ & $(n=40)$ \\
\hline $\mathrm{PVY}^{\mathrm{N}-\mathrm{Wilga}}$ & $84 \%$ & $(n=90)$ & $100 \%$ & $(n=57)$ & $99 \%$ & $(n=225)$ \\
\hline Rose end sprout & $83 \%$ & $(n=30)$ & $100 \%$ & $(n=23)$ & $100 \%$ & $(n=95)$ \\
\hline Middle sprout & $93 \%$ & $(n=30)$ & $100 \%$ & $(n=14)$ & $98 \%$ & $(n=72)$ \\
\hline Heel end sprout & $77 \%$ & $(n=30)$ & $100 \%$ & $(n=20)$ & $99 \%$ & $(n=58)$ \\
\hline Total & $77 \%$ & $(n=180)$ & $100 \%$ & $(n=108)$ & $74 \%$ & $(n=427)$ \\
\hline
\end{tabular}

early-inoculated plants (7 DAE) were infected (Fig. 3). This percentage was less than half for the plants inoculated 21 days after emergence (39\%), and even lower (13\%) for the late-inoculated plants (56 DAE). The percentage of infected progeny tubers harvested from non-inoculated stems of early-inoculated plants (7 DAE) was $89 \%$ $(n=35), 58 \%(n=12)$ from plants inoculated 14 days later, and $10 \%(n=10)$ from plants inoculated 56 DAE.

After inoculation of one stem, the virus migrated faster to the other stems of the plant when the inoculation was done shortly after emergence (7 DAE) compared to later inoculations (21 DAE). As shown in Fig. 4, the percentage of infected stems in plants inoculated 7 and 21 DAE is low, and not significantly different at one week and two weeks after inoculation $(p>0.05)$. Four weeks after inoculation, the percentage of infected stems in early-inoculated plants increased sharply, reaching around $71 \%$, while this percentage remained low $(10 \%)$ for the plants inoculated $21 \mathrm{DAE}$ $(p<0.001)$. The percentage of infected stems continued to increase 6 weeks after inoculation to reach $83 \%$ for the early-inoculated plants (7 DAE) and $30 \%$ for the late-inoculated plants (21 DAE). Due to the decay of the plants inoculated 56 days after emergence, the evolution of the percentage of infected stems could not be monitored properly until 6 weeks after inoculation, and therefore is not presented in Fig. 4. However, the evolution was slow, with no stems infected one and two weeks
Fig. 2 Probability of stem infection after inoculation, function of the inoculation schedule. Error bars present the standard error of the mean and " $n$ " values indicate the number of plants considered in the statistical analysis

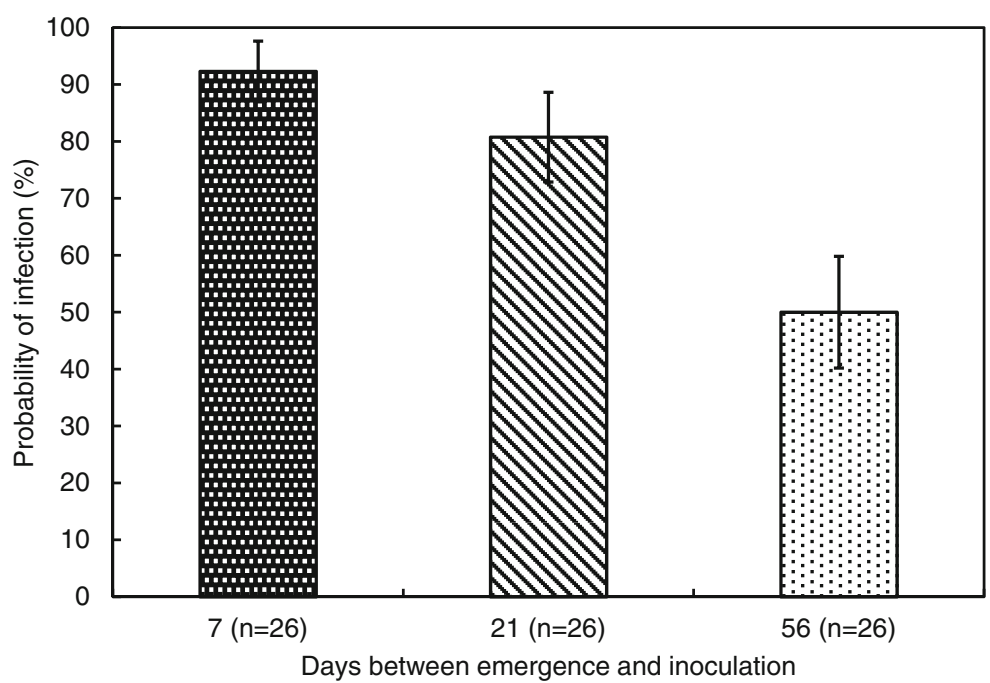


Fig. 3 Probability for noninoculated stems to get infected, function of the inoculation schedule. Error bars present the standard error of the mean and " $n$ " values indicate the number of plants considered in the statistical analysis

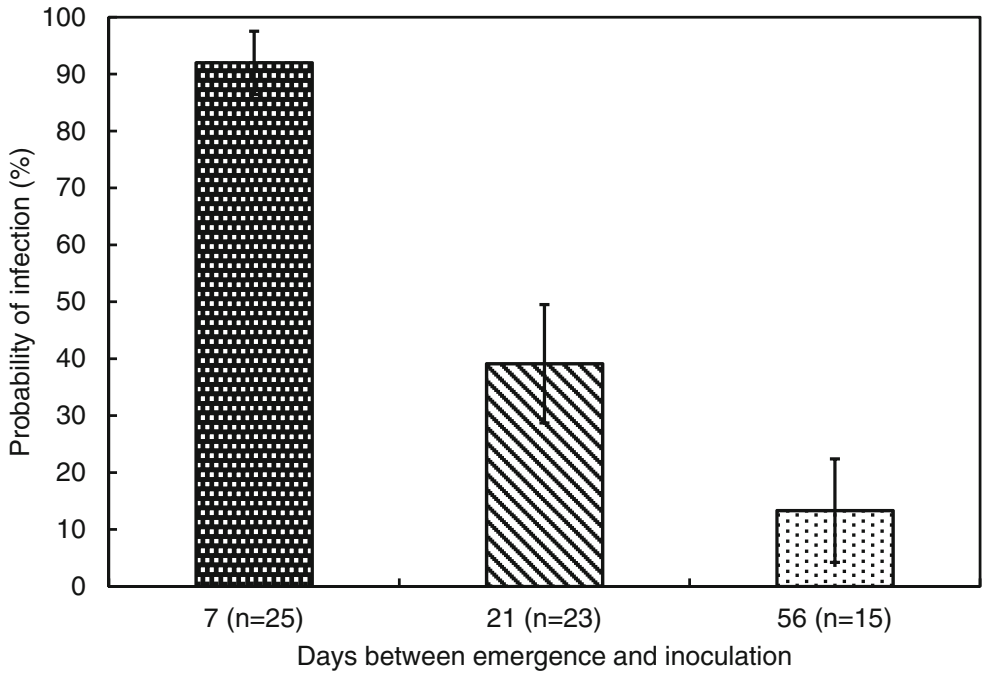

after inoculation and only $10 \%$ infected 4 weeks after inoculation.

From our results we could observe that the later the inoculation was done, the higher the yield was ( $p=0.001)$. Nevertheless, the model's coefficient of determination is low $\left(\mathrm{R}^{2}=0.3\right)$. Finally, no significant linear correspondence was found between the inoculation schedule and the number of progeny tubers harvested $\left(p>0.05 ; \mathrm{R}^{2}=0.042\right)$.

\section{Discussion}

The initial source of inoculum in the field is known to be the main risk factor for the subsequent spread of PVY to the healthy plants of the field (Steinger et al. 2014). The in-field source of inoculum comes from the infected seed tubers planted that offer PVY-infected foliage to the flying aphids, the vectors of the virus. Our results showed that all the stems of these tubers will become infected sooner or later. However, we also observed that not all the sprouts of an infected tuber are infected by PVY. We can hypothesize that the ELISA test was not sensitive enough to detect latent PVY infections in some of the sprouts, or that the virus came from other parts of the tuber and infected all the stems after the ELISA test. This suggests that all stems growing from an infected tuber will, eventually, become a source of inoculum in the field. In order to reduce the in-field sources of inoculum, it is generally recommended to remove the
Fig. 4 Evolution of the percentage of infected stems: 1,2 , 4 , and 6 weeks after inoculation for plants inoculated 7 and 20 days after emergence (DAE). Error bars present the standard error of the mean. Different letters indicate that the percentage of stems are different among the groups of plants inoculated at different dates $(p<0.05$ after analysis of variance ANOVA). "NS" indicates that the ANOVA results were not significant $(p>0.05)$

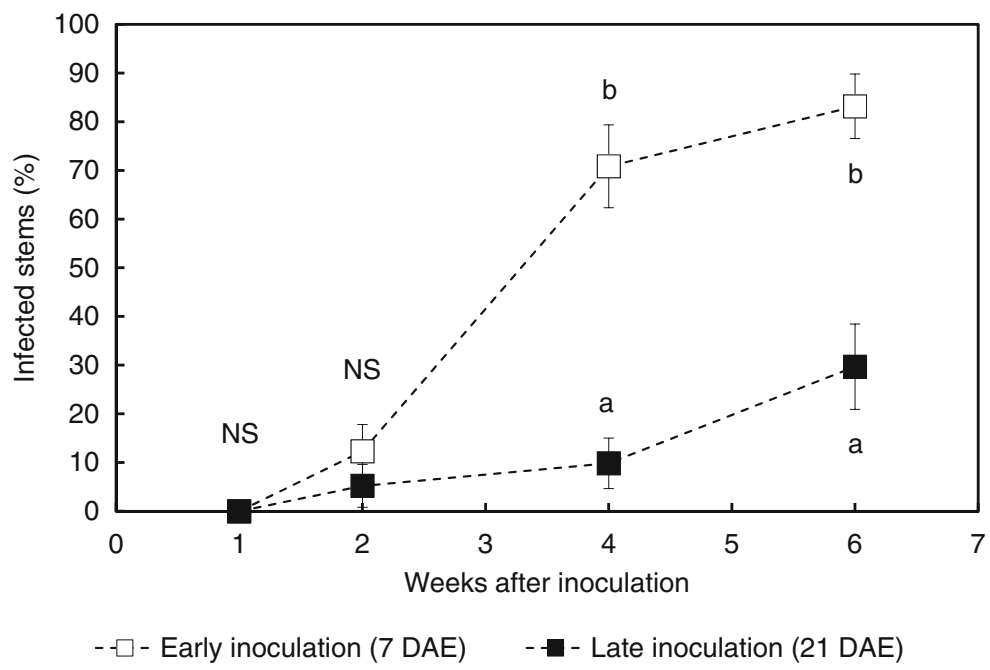


PVY-symptomatic plants as well as their progeny tubers (Davis et al. 2009). Some plants may, however, escape the vigilance of the seed grower and produce progeny tubers, which will present a risk for the following year. We also observed that the infection rate of these progeny tubers varied depending on the PVY strain. This variation of the infection rate is well-documented for primary infections (Sigvald 1985; Beemster 1976; Gibson 1991), and $\mathrm{PVY}^{\mathrm{N}}$ is known to be better transmitted to progeny tubers than $\mathrm{PVY}^{\mathrm{O}}$ (Beemster 1976). In our study we focused our research on secondary infections due to PVY strains which arrived recently in Europe and North America (Karasev and Gray 2013a; Glais et al. 2002). We showed that the $\mathrm{PVY}^{\mathrm{N}-\mathrm{Wilga}}$ strain is very efficient in transmitting the infection to the progeny tubers, and even more efficient than the PVY ${ }^{\mathrm{NTN}}$ strain. Note that it may be the case that the ELISA method may have missed some instances of low concentration of virus particles in some of the progeny tubers. However, this has no major implication for our main finding. In fact, while there may be cases where PVY ${ }^{\mathrm{NTN}}$ was not detected in progeny tubers, due to a low titer of the virus, $\mathrm{PVY}^{\mathrm{N}-\text { Wilga }}$ was detected in almost all progeny tubers, suggesting that the titer of $\mathrm{PVY}^{\mathrm{N}-W i l g a}$ virus particles was higher in those tubers. This information might explain why PVY ${ }^{\mathrm{N}-W i l g a}$ strains are increasing in prevalence in some European countries (Dupuis et al. 2013; Dupuis and Schwaerzel 2011; Rigotti et al. 2011; Lindner et al. 2015).

From our results we can also conclude that the probability of stem infection after inoculation was reduced for older stems. As noted above, this phenomenon is known as mature plant resistance and can be explained mainly by the restriction of cell-to-cell movement rather than a restriction of the replication of the virus (Draper et al. 2002; Valkonen and Rokka 1998). This resistance mechanism has important consequences for the epidemiology of PVY. In the case of aphid flights early in the season, young growing plants are particularly vulnerable to infections due to the absence of resistance. On the other hand, in the case of late aphid flights, the risk is reduced due to mature plant resistance, which will be at its maximum before senescence (Sigvald 1985; Gibson 1991; Robert et al. 2000).

Basky and Almasi (2005) previously observed that after primary infection of the sprouts, the virus was able to reach the other stems of the same mother tuber. Our results confirmed this observation, and additionally showed that the probability of stem infection through the vascular system of the mother tuber is significantly reduced with plant age. As mentioned above, the ELISA method used for this experiment may have missed some cases of PVY infections in part of the stems due to virus titers below the sensitivity threshold of the ELISA. However, a post-harvest analysis of progeny tubers grown from non-inoculated stems reveals that the percentage of infected tubers decreased sharply for late inoculations. These results are consistent with the ones obtained for the stems. Thus, our observations suggest a second mechanism of protection associated with mature plant resistance. This mechanism involves the vascular system of the mother tuber acting as a non-permanent bridge between the growing stems of the plant, and can be decomposed into two restriction elements that lower the transmission of the virus from one stem to the others through the vascular system of the mother tuber: a temporal restriction and a physical restriction.

Temporal restriction occurs when the virus does not have enough time to reach the mother tuber before haulm killing. As has been shown previously, cell-to-cell movement is slowed down in mature plants (Draper et al. 2002; Valkonen and Rokka 1998). In a case of late infection, the virus will thus take more time to reach the phloem parenchyma before being transported a longer distance by the movement on the sieve elements (Carrington et al. 1996). If the virus particles are not able to reach the phloem before haulm killing and plant desiccation, the virus will not be carried further to the other stems, and will not be able to infect them as well as their related progeny tubers. Our study supports this hypothesis, as for late infection (56 DAE), the probability for a healthy stem to get infected by virus particles drained through the mother tuber is low (a $13 \%$ chance in our trials).

On the other hand, physical restriction is present when the systemic movement of the sap through the vascular ring of the mother tuber is restricted by the collapsing of the mother tuber. Robert et al. (2000) suggested that this translocation through the mother tuber was slow and probably dependent on the mother tuber's stage of degeneration. Our results confirm this hypothesis, as it was observed that the probability for virus particles to be transmitted to healthy stems via the mother tuber decreases with plant aging. It was also observed at harvest that most of the mother tubers were decomposed (rotted or mummified), impeding sap transfer from one stem to the other (data not shown).

PVY is efficiently controlled by mineral and vegetable oil sprays (Dupuis et al. 2014; Powell 1992). Oil inhibits the acquisition of PVY by aphids and therefore 
reduces the risk of PVY transmission to healthy plants (Boquel et al. 2013). Oils are usually sprayed in potato fields every seven days. Given the high risk observed of transmitting the virus to all stems of the plant if the infection occurs in the second or third week following emergence, increasing the frequency of sprays during this period could be an option. Two oil sprays a week are carried out by some potato seed growers with success (Jean-Louis Rolot, personal communication), suggesting that more frequent applications might better protect the new leaves of the young, PVY-susceptible, and fast-growing plants. It will be necessary to reduce by half the quantity of oil sprayed for each treatment, in order to avoid any risk of phytotoxicity that an excess of oil may provoke (Boiteau and Singh 1982; Martin-Lopez et al. 2006).

Acknowledgments The author thanks Laure Sainthuile, Nicolas Pochon, Carole Morel, Ludovic Piccot, and Werner Wild for their technical support. I also thank Claude Bragard, Jennifer Cadby, and Fabio Mascher for their support in the editing of the document.

Open Access This article is distributed under the terms of the Creative Commons Attribution 4.0 International License (http:// creativecommons.org/licenses/by/4.0/), which permits unrestricted use, distribution, and reproduction in any medium, provided you give appropriate credit to the original author(s) and the source, provide a link to the Creative Commons license, and indicate if changes were made.

\section{References}

Basky, Z., \& Almasi, A. (2005). Differences in aphid transmissibility and translocation between PVYN and PVY0 isolates. Journal of Pest Science, 78(2), 67-75. doi:10.1007/s10340004-0070-5.

Beemster, A. B. R. (1976). Translocation of the potato viruses $\mathrm{Y}^{\mathrm{N}}$ and $\mathrm{Y}^{\mathrm{O}}$ in some potato varieties. Potato Research, 19(19), $169-172$.

Boiteau, G., \& Singh, R. P. (1982). Evaluation of mineral-oil sprays for reduction of virus $\mathrm{Y}$ spread in potatoes. American Potato Journal, 59(6), 253-262.

Boquel, S., Giguere, M. A., Clark, C., Nanayakkara, U., Zhang, J. H., \& Pelletier, Y. (2013). Effect of mineral oil on Potato virus Y acquisition by Rhopalosiphum padi. Entomologia Experimentalis et Applicata, 148(1), 48-55. doi:10.1111/ eea. 12070

Carrington, J. C., Kasschau, K. D., Mahajan, S. K., \& Schaad, M. C. (1996). Cell-to-cell and long-distance transport of viruses in plants. Plant Cell, 8(10), 1669-1681.

Cochran, W. G. (1950). The comparison of percentages in matched samples. Biometrika, 37(3/4), 10.

Dagnelie, P. (1975). Théorie et méthodes statistiques (Vol. 2). Gembloux, Belgium: Presses agronomiques de Gembloux.
Davis, J. A., Radcliffe, E. B., \& Ragsdale, D. W. (2009). Planter skips and impaired stand favors potato virus Y spread in potato. American Journal of Potato Research, 86(3), 203. doi:10.1007/s12230-009-9073-3.

Debokx, J. A. (1964). Onderzoekingen over het aantonen van aardappel- $Y^{N}$-virus met behulp van toetsplanten. Wageningen.

Draper, M. D., Pasche, J. S., \& Gudmestad, N. C. (2002). Factors influencing PVY development and disease expression in three potato cultivars. American Journal of Potato Research, 79(3), 155-165.

Dupuis, B., Balmelli, C., Buchwalder, A., \& Schumpp, O. (2013) Recent evolution of the potato virus $Y$ (PVY) populations in swiss seed potato production. In $\mathrm{V}$. Gaba, \& L. Tsror (Eds.), Phytopathology section meeting of the european association for potato research, Jerusalem, 17-21 November 2013 (pp. 74)

Dupuis, B., \& Schwaerzel, R. (2011) Potato Virus Y (PVY) strains spread and symptoms on plants and progeny tubers of potato cultivars. In The 18th Triennial Conference of the European Association for Potato Research, Oulu, Finland (pp. 115)

Dupuis, B., Schwaerzel, R., \& Derron, J. (2014). Efficacy of three strategies based on insecticide, oil and elicitor treatments in controlling aphid populations and potato virus Y epidemics in potato fields. Journal of Phytopathology, 162(1), 14-18. doi: 10.1111 jph. 12148 .

Fereres, A., \& Moreno, A. (2009). Behavioural aspects influencing plant virus transmission by homopteran insects. Virus Research, 141(2), 158-168. doi:10.1016/j.virusres.2008.10. 020.

Gibson, R. W. (1991). The development of mature plant-resistance in 4 potato cultivars against aphid-inoculated potato-virus $\mathrm{Y}^{\mathrm{O}}$ and $\mathrm{Y}^{\mathrm{n}}$ in 4 potato cultivars. Potato Research, 34(3), 205210.

Glais, L., Tribodet, M., \& Kerlan, C. (2002). Genomic variability in Potato potyvirus Y (PVY): evidence that (PVYW)-W-N and PVYNTN variants are single to multiple recombinants between PVYO and PVYN isolates. Archives of Virology, 147(2), 363-378.

Gray, S., De Boer, S., Lorenzen, J., Karasev, A., Whitworth, J., Nolte, P., et al. (2010). Potato virus Y: an evolving concern for potato crops in the United States and Canada. Plant Disease, 94(12), 1384-1397. doi:10.1094/Pdis-02-10-0124.

Gugerli, P., \& Gehriger, W. (1980). Enzyme-linked immunosorbent assay (ELISA) for the detection of potato leafroll virus and potato virus $\mathrm{Y}$ in potato tubers after artificial break of dormancy. Potato Research, 23(3), 353-359.

Karasev, A. V., \& Gray, S. M. (2013a). Continuous and emerging challenges of potato virus $\mathrm{Y}$ in potato. Annual Review of Phytopathology, 51(51), 571-586. doi:10.1146/annurevphyto-082712-102332.

Karasev, A. V., \& Gray, S. M. (2013b). Genetic Diversity of Potato virus Y Complex. American Journal of Potato Research, 90(1), 7-13. doi:10.1007/s12230-012-9287-7.

Lindner, K., Trautwein, F., Kellermann, A., \& Bauch, G. (2015). Potato virus Y (PVY) in seed potato certification. Journal of Plant Diseases and Protection, 122(3), 109-119.

Malnoe, P., Farinelli, L., Collet, G. F., \& Reust, W. (1994). Smallscale field test with transgenic potato, cv Bintje to test resistance to primary and secondary infections with potato virus Y. Plant Molecular Biology, 25(6), 963-975. 
Martin-Lopez, B., Varela, I., Marnotes, S., \& Cabaleiro, C. (2006). Use of oils combined with low doses of insecticide for the control of Myzus persicae and PVY epidemics. Pest Management Science, 62(4), 372-378.

Nolte, P., Whitworth, J. L., Thornton, M. K., \& McIntosh, C. S. (2004). Effect of seedborne Potato virus Y on performance of Russet Burbank, Russet Norkotah, and Shepody potato. Plant Disease, 88(3), 248-252.

Perez, I. (2011). Virus Protocol. https://research.cip.cgiar.org/ confluence/display/SET/Virus+Protocol. Accessed 27.04. 20142014.

Powell, G. (1992). The effect of mineral-oil on stylet activities and potato virus-Y tramsmission by aphids. Entomologia Experimentalis et Applicata, 63(3), 237-242.

Rigotti, S., Balmelli, C., \& Gugerli, P. (2011). Census report of the Potato Virus Y (PVY) population in Swiss seed potato production in 2003 and 2008. Potato Research, 54(2), 105-117. doi:10.1007/s11540-010-9183-9.

Rigotti, S., \& Gugerli, P. (2007). Rapid identification of potato virus Y strains by one-step triplex RT-PCR. Journal of Virological Methods, 140(1-2), 90-94. doi:10.1016/j. jviromet.2006.11.002.
Robert, Y., Woodford, J. A. T., \& Ducray-Bourdin, D. G. (2000). Some epidemiological approaches to the control of aphidborne virus diseases in seed potato crops in northern Europe. Virus Research, 71(1-2), 33-47.

Rolot, J.-L. (2005). Analyse des facteurs régulant la dissémination du virus Y de la pomme de terre (PVY) en vue de stratégies de lutte raisonnées. Gembloux: Faculté des Sciences agronomiques de Gembloux.

Schwaerzel, R., Torche, J.-M., Ballmer, T., Musa, T., \& Dupuis, B. (2014). Liste suisse des variétés de pommes de terre 2015. Recherche Agronomique Suisse, 5(11-12), 6.

Sigvald, R. (1985). Mature-plant resistance of potato plants against potato-virus $\mathrm{Y}^{\mathrm{o}}\left(\mathrm{PVY}^{\circ}\right)$. Potato Research, 28(2), 135-143.

Steinger, T., Gilliand, H., \& Hebeisen, T. (2014). Epidemiological analysis of risk factors for the spread of potato viruses in Switzerland. Annals of Applied Biology, 164(2), 200-207. doi:10.1111/aab.12096.

Valkonen, J. P. T., \& Rokka, V. M. (1998). Combination and expression of two virus resistance mechanisms in interspecific somatic hybrids of potato. Plant Science, 131(1), 85-94. doi:10.1016/s0168-9452(97)00238-0. 